\title{
ENERGY MANAGEMENT IN INDUSTRY 4.0 ECOSYSTEM: A REVIEW ON POSSIBILITIES AND CONCERNS
}

\author{
Milovan Medojevic, Pablo Díaz Villar, Ilija Cosic, \\ Aleksandar Rikalovic, Nemanja Sremcev \& Milovan Lazarevic
}
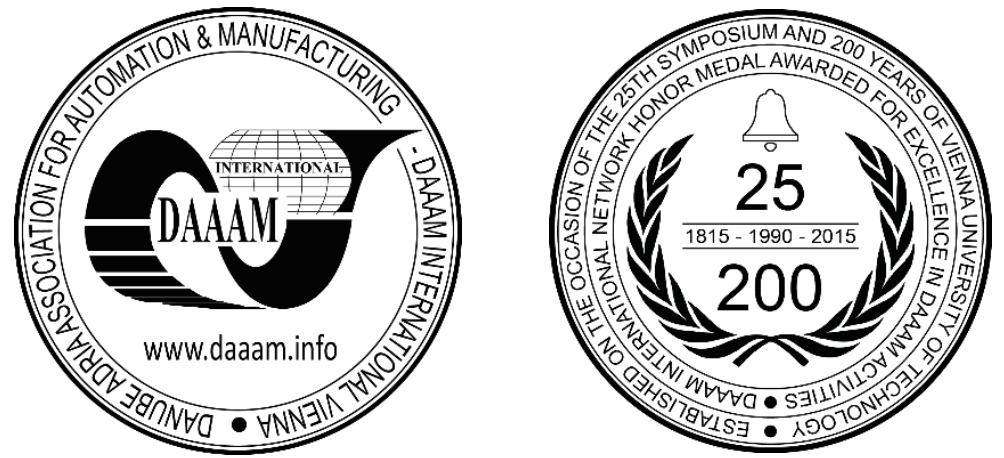

This Publication has to be referred as: Medojevic, M[ilovan]; Diaz Villar, P[ablo]; Cosic, I[lija]; Rikalovic, A[leksandar]; Sremcev, N[emanja] \& Lazarevic, M[ilovan] (2018). Energy Management in Industry 4.0 Ecosystem: a Review on Possibilities and Concerns, Proceedings of the 29th DAAAM International Symposium, pp.0674-0680, B. Katalinic (Ed.), Published by DAAAM International, ISBN 978-3-902734-20-4, ISSN 1726-9679, Vienna, Austria DOI: $10.2507 / 29$ th.daaam.proceedings.097

\begin{abstract}
It became more than evident that the era of Industry 4.0 is upon us, where industrial manufacturing companies are facing strong demand to increase their productivity by realizing smart factories and smart manufacturing. With the advantages of high-tech devices and solutions such as IPCs, industrial automation and machine automation technologies, hardware-software integration and various others, it is now possible to foster the development of Industry 4.0 through three logical steps. The first step considers the implementation of equipment connectivity: devices, machines, production lines and factories are connected to the system, and therefore, data transparency as well as information visualization can be obtained. In addition, the second step involves data collection and integration, as well as valued-added products and services that are introduced for smart manufacturing services. Lastly, the third step of intelligent innovative services is the enabling of intelligent machinery and big data analysis. Given the aforementioned, smart factory can be defined as a factory which harmonically implements Machine Automation, Equipment Monitoring \& Optimization, Machine Monitoring \& Predictive Maintenance, MES Integration \& Production Traceability, Factory Energy Management System and Factory Environment Monitoring - developed with integrated automation and cloud innovation for industry 4.0. Having in mind that the aim of this paper is to review the possibilities and concerns of Energy Management in Industry 4.0 Ecosystem, this topic will be devoted to the greatest attention, while the importance of other equally relevant topics that are simply not the subject of this review should not be diminished or underestimated.
\end{abstract}

Keywords: Industry 4.0; IoT; energy management; energy efficiency, energy modelling

\section{Introduction}

Industry 4.0, a German strategic initiative, is aimed at creating smart factories where manufacturing technologies are upgraded and transformed by cyber-physical systems (CPSs), the Internet of Things (IoT), cloud computing [1],[2], etc. In the Industry 4.0 era, manufacturing systems are able to monitor physical processes, create a so-called "digital twin" (or "cyber twin") of the physical world and make smart decisions through real-time communication and cooperation with humans, machines, sensors, and so forth [3]. 
Furthermore, Industry 4.0 combines embedded production system technologies with intelligent production processes to create a favourable climate for a new technological age that will fundamentally transform industry value chains, production value chains, and business models. To be more precise, it became obvious that the factors driving Industry 4.0 are paving the way for intelligent energy management. When companies embark on efforts to introduce Industry 4.0, they mostly focus on the 'core' parameters of production efficiency, quality and cost. This is obviously what drives revenue. However, there is a strong case to also include energy management in such projects. After all, systematically tracking energy consumption, production and costs is a major challenge nowadays in most industries - and one that has a lot in common with Industry 4.0 thinking. Therefore, in the development of Industry 4.0, energy management and energy efficiency overall has taken centre stage. As a matter of fact, knowing the regulations, specific energy needs and increasing importance of energy to drive the smart factory and smart industry, there is more attention than ever for energy efficiency in industrial markets.

While improved energy efficiency, as well as effectively implemented Energy Management System, is always welcome, it is rarely the main driver of Industry 4.0 deployments. However, energy savings have been reported by those organizations that have attempted to make Industry 4.0 a reality. For example, Daimler in Germany has reported a $30 \%$ improvement in energy efficiency for its robot systems that use Industry 4.0 techniques. Another example is Canadian Forest Products, which reported a $15 \%$ reduction in energy consumption by using real-time alerts for energy consumption outside of anticipated norms.

Hereinafter, this paper presents a review of the main concepts of the industry 4.0 and the benefits and drawback that their implementation has on energy management in manufacturing.

\section{Concepts of Industry 4.0 and their implications on Energy Management}

In the context of Industry 4.0, the path of a to-be-manufactured object is shaped by complex analysis and simulation tools used by production engineers, leading to well defined manufacturing processes. These processes define the production technique, machines, chronology, materials and many other manufacturing parameters long before the to-bemanufactured object physically enters the factory. In order to achieve this, engineers relay on modern technology concepts which are briefly introduced below. It should be noted that the following concepts are dominant ones, which does not mean that those who are not mentioned have a minor significance.

\subsection{C1 - Internet of Things (IoT)}

First coined by Ashton in 1999, the Internet of Things is a concept describing the next iteration of the internet, where information and data are no longer predominantly generated and processed by humans - which has been the case for most of the data created so far [4] - but by a network of interconnected so-called smart objects, embedded sensors and miniaturized computers, able to sense their environment, process data, and engage in machine-to-machine communication. This is already exemplified in our everyday life by connected watches or cars, while industrial applications include use of interconnected sensors in order to continuously monitor process parameters (e.g. pH, temperature, relative humidity, etc.) and enable real-time or even pre-emptive maintenance, hence reducing costs, improving efficiency and enabling better quality and safety standards.

\subsection{C2 - Big Data}

Big Data is a term often used to describe sets of data characterized by high volume, high velocity, and high variety [5], and for which the use of advanced analytical tools is required in order to process data into actionable information by identifying patterns, trends, and relationships [6].

Big data is a consequence of the continuous and increasing production of data, spurred in particular by the vast deployment of digital platforms and applications in everyday life. Examples include, new analytical devices (e.g. in the medical sector), as well as the increased number of sensors and connected objects (IoT) which continuously generate large amounts of data. However, it is estimated that less than $1 \%$ of all available data is currently analysed [7]. Big data therefore creates important challenges and opportunities now and in the coming years.

Big data could support sustainability, for instance by helping produce relevant statistics that enable better informed decision making as much on economic, environmental or societal issues.

\subsection{C3 - Augmented Reality}

One big potential for Augmented Reality (AR) is seen in the service sector. Its application for maintenance purposes can help to connect staff on the customer location with service experts from the producing company, allowing them to jointly inspect the product under consideration and develop feasible maintenance solutions, without forcing experts to physically travel to the customer. The same approach can be applied when it comes to training of local workforces in different regions. Through these approaches AR applications open up economic opportunities for small companies like start-ups, which want to sell their product around the globe and to offer decent services to their customers, but cannot afford to establish a global service network [8]. 
Recently, a wide spread of AR use in energy management systems through "Open Energy" concept is noticed [9]. "Open Energy" is an open-source energy infrastructure, designed as a platform to explore new systems of energy use visualization and its optimization for both residential and industrial environments. The system consists of a hardware energy monitoring device and a software real-time data visualization utility based on AR application. Another interesting application of AR to promote energy efficient building solutions is the Lobby Showcase of the Fraunhofer Center for Sustainable Energy Systems (CSE) [10], where thousands of sensors are placed inside and outside of their headquarters, ensuring $5 \mathrm{CC}$ building to become living laboratory gathering and sharing live data.

\subsection{C4 - Blockchain}

Blockchains are distributed databases and ledgers made of blocks stored on a large number of machines, so that any changes made to the database are permanently recorded, and any record is made publicly available thanks to the distributed design [11]. Blockchains are expected to bring about unprecedented changes in traceability and data robustness. This opens up new opportunities for reducing or eliminating the need for a trusted middleman in many operations, ensuring a supply of certified renewable electricity coming from distributed energy generation, the verification of legal energy provisions, etc. From the aspect of energy management, Blockchain technology provides companies with the potential to analyse their energy consumption with greater accuracy and efficiency, monetize the data collected and validate energy consumption and savings in real-time. Also, this technology provides a new solution to record and monetize carbon credits where applicable. In addition, Blockchain can be an important technology solution for the energy management sector by playing a role in providing real-time access to energy savings, transparent recording of energy transactions and an immutable record of GHG emission savings. Rising electricity costs and energy sustainability are a critical risk for factory owners and asset managers worldwide.

According to a recent study, German energy executives see a wide range of possible applications for blockchains in the energy sector and believe the technology could have the potential to reduce costs and spur new business models in it [12]. However, the blockchain technology faces many challenges, in particular privacy and data security issues, but also technical issues such as the currently still rather long time needed to conduct a transaction. Besides, services based on blockchain have to prove competitive with existing solutions and need to convince users of their attractiveness [12]. However, there are already a number of start-ups, working on solving these challenges and on providing blockchain solutions for the energy sector [8].

\subsection{C5 - Rapid Prototyping}

Rapid prototyping is a group of complementary technologies such as computer-aided design and additive-layers manufacturing, also known as 3D-printing, used to rapidly produce parts and prototypes, as opposed to the more traditional material forming and removal techniques [13]. The cost and time savings enabled by rapid prototyping can help to ease mass-customization and are considered an enabler for innovation, as innovative designs are becoming easier, quicker, and less expensive to test. Beyond prototyping, technologies such as additive-layer manufacturing also provide benefits to serial or mass manufacturing processes, as exemplified by General Electric's LEAP engine where 3D-printed fuel nozzles have enabled to go from 18 sub-parts to only 1[8]. This not only multiplied the durability of the component by $5 \%$ and reduced its weight by $25 \%$, but also enabled a better optimised geometry to achieve higher combustion efficiency [14], leading to fuel savings throughout the life of the engine and reducing its $\mathrm{CO}_{2}$ emissions.

\section{Energy Management integration in Industry 4.0: Energy Management 4.0}

As already mentioned, for manufacturers to be competitive in the $4^{\text {th }}$ industrial revolution, reducing production costs is of crucial importance. One way to achieve this is by creating a solid strategy when it comes to energy management in industry 4.0. Although it is of vital importance to establish a solid industrial ecosystem that contributes to a high percentage of national GDP, unfortunately in the last decades a decrease in industry's overall added value and a dwindling social impact is present, while unemployment figures have skyrocketed.

Among many factors that need to be optimised in order to stay competitive, one is energy efficiency which is still easily forgotten in most companies.

Nowadays, manufacturing systems worldwide implement advanced manufacturing or Lean Manufacturing principles, in which minimal resources to bring maximum value to the business are applied. These same principles can and should be used for energy utilization. From this perspective, it is all about being efficient in the way the energy within manufacturing system is being used, with aim to reduce consumption where necessary, and transfer adequate knowledge to relevant personnel across the organisation in order to bring the same value with less energy.

With regards to energy management and energy efficiency in Industry 4.0, staying within the context of factories and facilities and not the broader Energy 4.0 picture (which is essential too, nevertheless), there is more than just a sheer need for energy availability, reliability, quality and manageability. This is driven by a mix of environmental factors, cost challenges, regulations and so forth, indicated in the attention for proactive energy consumption capabilities (which is partially about regulations) and the integration of alternative sources of energy which has never been higher and is even poised to increase. 
The modern society reached another development stage where over time, as energy become an increasingly digital given with sensors, while also becoming more decentralized with energy coming from a local solar photovoltaic, wind or microgrid systems, users are able to have even more control and ability to manage their energy usage.

Energy availability and reliability are not just important for critical energy buildings, manufacturing processes and all the other mission-critical operations in the scope of Industry 4.0. They are an essential part of it. Or in other words, without energy management overall at the center of Industry 4.0 there is no Industry 4.0.

While traditional industrial energy management focuses on the efficient provision and use of process energy needs, such as heating, cooling, compressed air, and electricity, the IoT has a wealth of new data streams to support energy management measures. However, manufacturing systems may be slower to adopt some of these technologies than the consumer market due to a greater familiarity with the use of sensors and automation. This is mainly due to the fact that a key driver for the digital transformation for the manufacturing systems is maintaining global competitiveness and technological advances, therefore forcing the alignment of production and wider business processes through the tools that offer new possibilities for business models.

For example, to increase reliability and efficiency, and to gain other operating benefits, such as reduced maintenance and improved safety, many facilities are turning to IoT. Technologies, such as acoustic monitoring of steam traps, condition monitoring of pumps, and heat exchanger performance, all wirelessly connected to supervisory control, data acquisition and analytics systems, provide cost-effective installation and paybacks of less than six months in most cases.

In addition, a new generation of software tools for energy efficiency allows differ two types of industrial energy management: open loop, where the optimal set points are indicated to the operators to manually set the optimization variables; or closed loop, where the set points are sent directly to each optimizable variable. These implementations can typically achieve energy-cost reductions from 3 to 8 percent for the open-loop model, and 6 to 15 percent for closedloop applications [15].

Considering all of the above, the basic steps to implement energy management in industry 4.0 are starting from understanding energy flows and consumption upon which is possible to identify which consumptions and consumers are unnecessary or excessive. Then, adequate indicators and real time monitoring system, necessary for creating a favourable climate for application of continuous improvement tactics to make action plans managed with continuous improvement methodology, could be established [16]. However, it is important to notice that, from the organization of the manufacturing systems perspective, manufacturing activities can be considered as being composed of at multiple levels [17]. Therefore, the choice of system abstraction levels depends on the goal of the optimization research and on the specific hierarchy levels. Each of these hierarchical levels is quite different regarding the necessary data knowledge, methods and tools for planning, design and controlling as has illustratively been given in Figure 1.
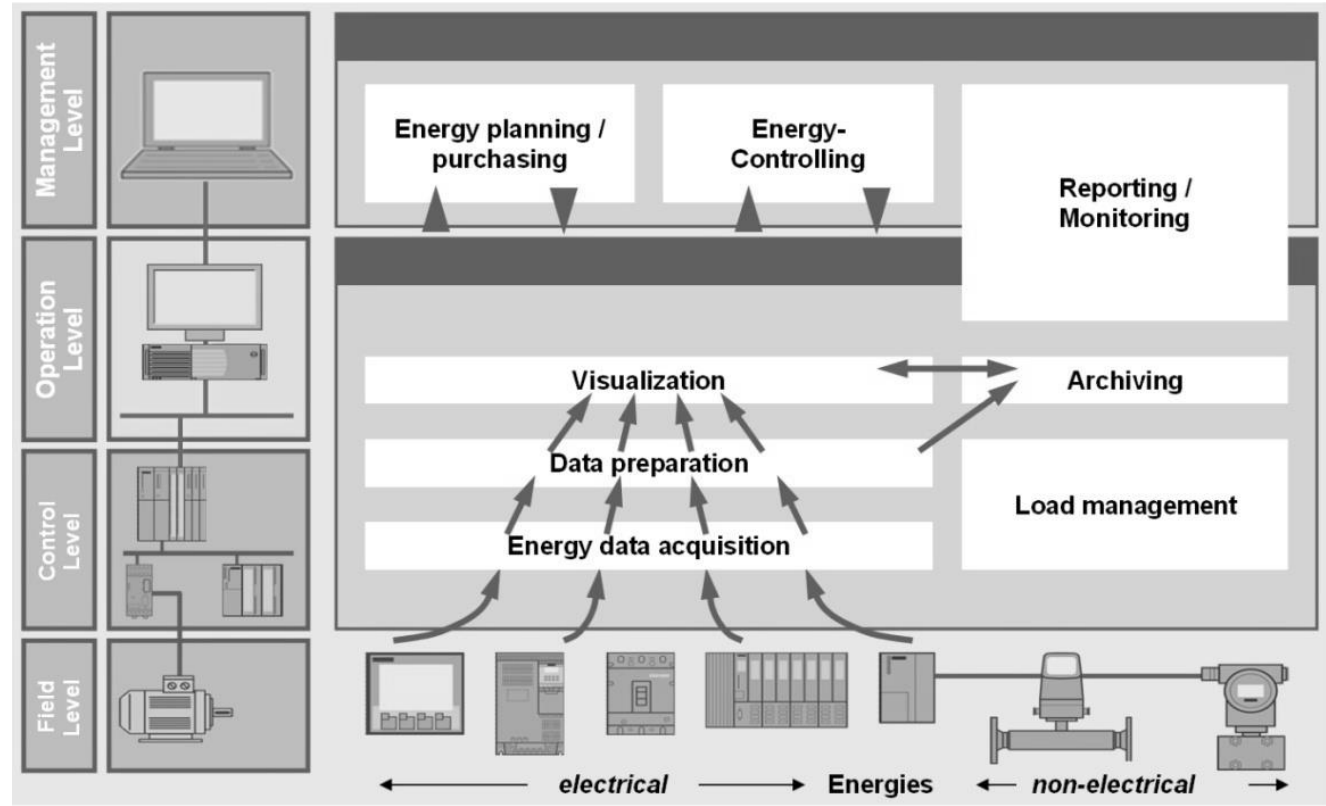

Fig. 1. Example of general components for energy efficiency and energy management [18]

Each level also involves several possibilities to influence the energy efficiency which are, again, very different regarding their individual effects. Specifically in the context of energy and resource consumption typically different disciplines (e.g. production engineering, industrial engineering, business administration, thermodynamics, material science) and internal (different departments, management) and external stakeholders (e.g. customer, supplier, politics) have their specific set of objectives. This leads to a complex system of systems with dynamic interactions and interdependencies that need to be balanced from a holistic point of view in order to avoid problem shifting, local optimization and modelling [19], [20]. 


\section{Advanced energy modelling based on IoT}

The digital world delivers more actionable data than ever before, where replacing gut feeling with real-time and comprehensive data leads to better decision making. Whether this is about projects to fund, plant utilization, or sales accounts to focus on, data will be available to evaluate and select.

To gain the benefit of the IoT, though, it is prerequisite to have an in-depth understanding of observed processes and to identify parameters which are critical to the energy and productivity performance of such. Although this may seem obvious, many organizations have a poor understanding of the relationship of energy use to operational settings. Those who have deployed the IoT and Industry 4.0 realized that the digitization of the manufacturing processes allowed them to better understand the actual energy demand of their machines.

Interpretation of data flows is a critical aspect. Information overload is an issue across all industrial sectors. When alarms are sounded, an appropriate set of options must be available to operators to gain potential savings. Impressive looking dashboards are only useful if they lead to appropriate actions. However, identifying these sets of appropriate actions is quite often excluded from data acquisition and reporting projects. Reporting often focuses on middle and senior management needs, rather than on the operators who ultimately decide if savings will be realized or not (as indicated in Fig. 1.

It is all about data. Fundamentally both Industry 4.0 and energy management are about collecting, using and combining data to look for optimization. A typical factory sits on a treasure trove of data - which it does not use. The efforts and investment needed to start mining this information are very similar. Because energy management requires a very specific context and skill set that are not the core business of average factory, it is not automatically included in projects. For the same reasons many industrial data mining software packages offer no or only rudimentary modules for working with energy information. On the other hand, it does not have to be like this. By integrating relevant data generated through IoT devices, specially tailored models of factory energy consumption could be established, upon which specific process simulations could be developed and implemented in order to validate the system performance before actual production process. This is of great importance for model-based and data-driven prognostics.

Model-Based prognostics approaches are mainly based on analytical/mathematical models to describe behaviours of systems and mechanisms of degradation phenomenon [21], [22]. Main advantages of model-based approaches are their high accuracy and flexibility in configuring input data. Of course, prediction accuracy of these approaches depends on the precision of the presented models. Furthermore, nonlinear and stochastic characteristics of industrial systems may increase the difficulty in factory analytical models. The flexible configuration of systems impacts the model parameters. Thus, these situations have to be taken into account in the real-time modifications of these models.

On the other hand, data-driven prognostics approaches allow to identify trends/patents of a developing fault and to predict the amount of time before it reaches a predetermined threshold [23]-[25] using information from historical treated data (trained data). These prognostic approaches can identify the real-time health condition of a system by various techniques such as regression analyses, Bayesian algorithms, neutral networks, fuzzy logics, support vector machine and so forth. These prognostic approaches are precise in their ability to link with recognized system behaviours by experience methods. Despite no specific physical model is needed, the data-driven approaches require a monitoring system and learning time which can be insured by applying variety of existing IoT solutions.

Given the aforementioned, especially focusing on availability of real-time data thanks to IoT solutions, energy consumption could be observed and treated as a stochastic process with the Markov property, where the term "Markov chain" refers to the sequence of random variables such a process moves through, with the Markov property defining serial dependence only between adjacent periods (as in a "chain"). It can thus be used for describing systems that follow a chain of linked events, where what happens next depends only on the current state of the system.

Here, Markov prediction uses the stochastic process change law to perform prediction, while the adequate decision could be made based on the present state of the system.

\section{Challenges associated with energy-efficient Industry 4.0}

It is reckless to think that the high potential of Industry 4.0 for transforming industrial processes and economy do not come without challenges. Public discourse especially in early industrialized countries has particularly focused on the question of how digitization may affect the "future of work", in terms of both quality and quantity of jobs, but also the work relationship between humans and machines [8]. Beside obvious benefits, favoured in this review, an inherent conflict could arise in human-machine-interaction: in such a way that humans are being slaved to follow decisions of machines they cannot fully comprehend anymore, which could likely lead to frustration, at least.

Besides, digitization could not only alter and reduce employment in some sectors, but also create new jobs, though this is not exclusively common with positive effects.

In addition, resource demand issue is imposed for special attention due to the fact that every digital device is based on hardware that requires raw materials for its original production. Consequently, the growing diffusion and application of digital technologies, the demand for raw materials is also likely to increase, popping out the questions regarding their availability. The study conducted by the German Mineral Resources Agency forecasts that in 2035 the most crucial materials are likely to be Lithium and Heavy Rare Earths [26]. 
The most sensitive issue is however data security \& privacy as one of the biggest challenges most often expressed by companies in association with Industry 4.0 [27]. This is due to a intensive fear of becoming more vulnerable to hackers invades on their intellectual property as they have digitized their processes and connected all devices and machines to network. A less prominent challenge is to maintain and guarantee the privacy of employees, who will also contribute a lot of personal data, when constantly interacting with permanently connected devices.

Overstraining of governments with the creation of suitable policy frameworks is also present. Digitization and Industry 4.0 are largely driven by actors from the economic sphere. Their pace often exceeds the speed at which policies and regulations can be formulated to govern digital and technology developments. In this way, policy making could become ineffective in impeding potential adverse effects, e.g. on privacy and data security, labour rights, conditions and the environment. Also, the exponential growth of technology development could lead to a first-mover advantage for pioneering companies. This would give the few top runners large economic influence and - if regulations are weak power to lever out social and environmental standards. Companies will therefore not only be increasingly challenged to provide suitable framework conditions for innovation, but also to protect existing standards and to expand them to newly developing digital branches.

On a broader picture, inequalities between the economic development of industrialized, emerging economies and developing countries could further deepen if countries of the Global South cannot tap into digital development benefits. Developing and least developed countries should be enabled to use the possibilities of ICT and Industry 4.0 to achieve their development priorities.

\section{Conclusion}

Despite the obvious similarities and the huge potential, energy management is not (yet) fully incorporated in most factory digitization projects. Changing this will require two things. First of all the awareness with plant managers that the two themes are intimately connected is needed to be achieved. Secondly, and more importantly, the software tools that are available need a major upgrade. The crux lies in fully mapping energy data on the structure of production processes. There is reason for optimism, though. Awareness is growing quickly with key decision makers in industry.

Likewise, optimized decision making provides an accurate allocation of energy cost to the products and the work centers they are produced in. These considerations are important and minimize costs. Historically, production managers have not been able to bring actual energy or water consumption into the equation to determine which machine is the best to run certain products in. With an Intelligent Energy Management System, those actual numbers become part of the equation. This provides a completely new dimension in the decision process.

Having this in mind, the Internet of Things, Industry 4.0, and energy management combined together are like a heady cocktail that suggests an exciting future with reduced costs and improved performance. However, as is the case with any cocktail, you could be left with a severe hangover, wondering where all the promise and money went. This means that manufacturing managers should be taking full advantage of these tracking tools for Energy Management System carefully.

The profitable opportunities mentioned above are obtainable for any factory. However, it is needed to make an initial investment in Energy Management because going green and being energy efficient is no longer just a phase of the manufacturing market, it becomes the new standard policy for leading companies within Industry 4.0 around the world.

Last but not the least, ever present problems in industrial automation field such as inability to perform complicated or non-repetitive tasks, high initial costs, adequate and structured knowledge-based maintenance and training platform, represent still main limitations in the scientific literature. Even though machines offer increases in quality and redundancy, current automation technology has been unable to address the issue of complex production. Humans, at least at this point in time, are the only workers capable of performing customizable or complex production tasks. Additionally, while automated machines will ultimately provide savings and efficiency in the long run, they do require a significant initial investment, making it hard to integrate into overall budget. The present findings also confirm that like in every technology transition, current personnel will need to be trained to properly implement, operate and maintain these intelligent systems in order to ensure their continued functionality.

Finally, future investigations are necessary to validate the kinds of conclusions that can be drawn from this study. Therefore, future research should be conducted in more realistic settings with aim to further develop and confirm initial findings. This could be achieved through development of small-scale smart factory physical model, based on aforementioned concepts of Industry 4.0. This could help creation of creative environment from where variety of research questions could appear not only related to energy matter, it could lead to generation of new technological ideas, as well as to new methodologies for problem solving. The exponential function of technological development became peaking steep with strong pressure to eliminate boundaries between production and management, providing that ERP, MES and other critical systems are integrated to realize the growth opportunities that this new age of intelligent manufacturing brought upon us.

\section{References}

[1] Lee, J., Bagheri, B., Kao, HA. (2015). A cyber-physical systems architecture for industry 4.0-based manufacturing systems, Manufacturing Letters, Vol. 3., January 2015., 18-23, ISSN: 2213-8463. 
[2] Lasi, H., Fettke, P., Kemper, HG., Feld, T., Hoffmann, M. (2014). Industry 4.0. Business \& Information Systems Engineering, Vol. 6, Jun 2014, 239-242, ISSN: 2363-7005.

[3] Wang S, Wan J, Zhang D, Li D, Zhang C. (2016). Towards smart factory for Industry 4.0: A self-organized multiagent system with big data based feedback and coordination. Computer Networks, Vol. 101., June 2016, 158-168, ISSN: $1389-1286$.

[4] Ashton, K. (2009). That "Internet of Things" Thing,RFiD Journal, Vol. 22, 2009.,97-114.

[5] De Mauro, A., Greco, M., Grimaldi, M. (2014). What is big data? A consensual definition and a review of key research topics, International Conference on Integrated Information (IC-ININFO 2014), AIP Conference Proceedings 1644, 97, Madrid, September 5-8, 2014,doi: 10.1063/1.4907823

[6] Lycett, M. (2013). 'Datafication': making sense of (big) data in a complex world, European Journal of Information Systems, Vol. 22., No. 4., 381-386, ISSN: 1476-9344.

[7] Gantz, J., Reinsel, D. (2012). The Digital Universe in 2020: Big Data, Bigger Digital Shadows, and Biggest Growth in the Far East United States, IDC.

[8] Nagasawa, T., Pillay, C., Beier, G., Fritzsche, K., Pougel, F., Takama, T., The, K., Bobashev, I. (2017). Accelerating clean energy through Industry 4.0: Manufacturing the next revolution, UNIDO.

[9] Brackney, L. J. (2010). Augmented reality building operationstool, Nov. 2010. US Patent App. 12/946,455.

[10] Nguyen, T. D. (2013). Augmented Reality for Building Technology, Diploma thesis, Karlsruhe Institute of Technology.

[11] Crosby, M., Nachiappan, Pattanayak, P., Verma, S., Kalyanaraman, V. (2016). Blockchain technology: Beyond bitcoin, Applied Innovation Review, June 2016, Issue No. 2, Sutardja Center for Entrepeneurship and Technology, Berkeley.

[12] Burger, C., Kuhlmann , A., Richard , P., Weinmann, J. (2016). Blockchain in the energy transition: A survey among decision makers in the German energy industry, Deutsche Energie-Agentur GmbH (dena) - German Energy Agency: Energy Systems and Energy Services, Berlin, pp. 44.

[13] Kruth, J.P., Leu, M.C., Nakagawa, T. (1998). Progress in Additive Manufacturing and Rapid Prototyping, CIRP Annals, Vol. 47, Issue 2, 1998, 525-540, ISSN: 0007-8506.

[14] Ford, S., Despeisse, M. (2016). Additive manufacturing and sustainability: an exploratory study of the advantages and challenges, Journal of Cleaner Production, Vol. 137, 20 November 2016, 1573-1587, ISSN: 0959-6526.

[15] Dwyer, B., Bassa, J. (2018). Combining IoT, Industry 4.0, and energy management suggests exciting future, InTech Magazine, Mar-Apr 2018, ISA Publications.

[16] Medojevic, M., Medojevic, M., Cosic, I., Lazarevic, M., Dakic, D. (2017). Determination and Analysis of Energy Efficiency Potential in Socks Manufacturing System, Proceedings of the 28th DAAAM International Symposium, pp.0582-0591, B. Katalinic (Ed.), Published by DAAAM International, ISBN 978-3-902734-11-2, ISSN 17269679, Vienna, Austria, DOI: 10.2507/28th.daaam.proceedings.082

[17] Duflou, J.R., Sutherland, J.W., Dornfeld, D., Herrman, C., Jeswiet, J., Kara, S., Hauschild, M., Kellensa, K. (2012). Towards energy and resource efficient manufacturing: A processes and systems approach, CIRP Annals Manufacturing Technology, Vol. 61, No. 2, 587-609, ISSN: 0007-8506.

[18] Siemens. (2011). Energy Management and Energy Optimization in the Process Industry: White paper, Siemens, Sector Industry, IA AS S MP 7. (C) Siemens AG 2011.

[19] Fang, K., (2011). A New Shop Scheduling Approach in Support of Sustainable Manufacturing, in Glocalized Solutions for Sustainability in Manufacturing, J. Hesselbach and C. Herrmann, Editors. 2011, Springer Berlin Heidelberg. p. 305-310, ISBN 978-3-642-19692-8.

[20] Kara, S., Li, W. (2011). Unit process energy consumption models for material removal processes, CIRP Annals Manufacturing Technology, Vol. 60, No. 1, pp. 37-40.

[21] Medjaher, K., Skima, H., Zerhouni, N. (2014). Condition assessment and fault prognostics of microelectromechanical systems, Microelectronics Reliability, Vol. 54, No. 1, pp. 143-151.

[22] Kusiak, A., Tang, F., Xu, G. (2011). Multi-objective optimization of HVAC system with an evolutionary computation algorithm, Energy, Vol. 36, No. 5, pp. 2440-2449.

[23] Goebel, K., Saha, B., Saxena, A. (2008). A comparison of three data-driven techniques for prognostics, in 62nd Meeting of the Society for Machinery Failure Prevention Technology, pp. 1-13.

[24] Sankararaman, S., Goebel, K. (2014). An Uncertainty Quantification Framework for Prognostics and Condition-Based Monitoring, in 16th AIAA Non-Deterministic Approaches Conference, pp. 1-9.

[25] Si, X.S., Wang, W., Hu, C.H., Zhou, D.H. Remaining useful life estimation - A review on the statistical data driven approaches, European Journal of Operational Research, Vol. 213, No. 1, pp. 1-14.

[26] Marscheider-Weidemann, F., Langkau, S., Hummen, T., Erdmann, L., Tercero Espinoza, L. (2016). Raw materials for emerging technologies 2016 (commissioned study), DERA Rohstoffinformationen 28: 13 S., Berlin, ISSN: 2193-5319.

[27] Brink, S., Schlepphorst, S. \& Bijedic, T. (2015). Die Digitalisierung im Mittelstand.” BDI-PwCMittelstandspanel. 